Vol. 8, Issue 8, August 2021

DOI: $10.17148 / I A R J S E T .2021 .8866$

\title{
Social Media Affects Health Behavior
}

\author{
Dr. S. Meenakshi ${ }^{1}$ \\ ${ }^{1}$ Assistant Professor, Department of Computer Applications, SDNB Vaishnav College, Chennai, Tamilnadu
}

\begin{abstract}
Social impacts are a major factor in the adoption of health activities. Passivity with diet and nutrition plans, observance to precautionary screening commendations, and upkeep of workout procedures all can be reliant on having communication with friends and family who also involve in these activities. In accumulation to a great agreement of literature on peer effects, current studies of huge network have made significant improvements in our empathetic of how social networks influence the combined changing aspects of health behaviour.

Research studies has shown that societal effects can disturb combined health consequences extending from widespread obesity to smoking behaviours, which have significant concerns for the hands-on proposal of interferences and dealing approaches The big quantity of health areas pretentious by current investigation on the blowout of behaviours has made common dissemination a matter of increasing attention for an cumulative change of researchers who are bothered with $\mathrm{c}$ the social dimensions of health.

This paper discourses the growth of novel methods that use social media to learning these health changing aspects and address collective concerns about negative influence of social media on mental health.
\end{abstract}

Keywords:Social Media, Health Behaviors

INTRODUCTION \& LITERATURE

A countless deal of studies in social infectious studies the ways in which structural, topographic, communal, and economic limitations can seriously influence patients' health consequences. This investigation has discovered that a vital variant effecting population health can be gained knowledge about and approach to medical treatments and investigations. For example, researches have shown that medical practices can be extremely confined, diversified enormously from one topographic zone to another. Accordingly, details about medicaments, and televise may be out of proportionately accessible to some people and not to others. The exceptional development of Internet-based health and health communities allows patients from a diversity of communal and topographic backgrounds to spare knowledge about modern health sources, varying from knowledge about diet and nourishment to occasions to know about patient encouragement, precautionary health screens, and modern cure technologies.

In spite of this, social networks such as Facebook, Twitter, Google+, and other social tools have created new chances to find the exchanges between social and health. Latest studies using social networks has delivered imperative new understandings into the changing aspects of opinion broadcast on health activities. For example, investigation on Twitter networks have discovered that soppiness about vaccines can be broadcasted through links of Twitter feeds. Likewise, approaches toward smoking, weight loss, and cholesterol and blood pressure medicines can also have a significant impact. The strengthening and dispersion of approaches has significant effects for the kinds of anticipatory behaviors that people are eager to involve in, predominantly when the activities are challenging or expensive.

Studies into this scenario advocates the act of studying about others' health practices may be incredibly helpful to those facing health problems themselves. Interpretation of blogs or viewing vlogs on the individual health problems of others of their same age may develop young people's health literateness, rapid individuals to use relevant health facilities and support persons to better understand their own health conditions or make improved health options. Health movements can gain authority through communal advancement on social media, and the precise individual nature of someone sharing their practices can offer others with practical approaches and handling mechanisms.

$45 \%$ of people using social media and digital medicinal data foundations have confidence that the tools have assisted them accomplish a better health consequences.

$70 \%$ of social media users said they watched online for health data within the past year 


\section{International Advanced Research Journal in Science, Engineering and Technology}

Vol. 8, Issue 8, August 2021

DOI: 10.17148/IARJSET.2021.8866

The percentage of adult users who used internet for the below reasons.

\begin{tabular}{|l|}
\hline Specific disease or medical problem \\
\hline Particular medical treatment \\
\hline How to control weight \\
\hline Health Insurance \\
\hline Food Safety \\
\hline Medicine Safety \\
\hline Medical Test Results \\
\hline Pregnancy or Child Birth \\
\hline
\end{tabular}

How online searches affect health decisions?

- $\quad$ Exaggerated a result about how to treat a disease.

- $\quad$ Transformed complete method for upholding health

- $\quad$ Directed to ask new questions or getting a second opinion

- $\quad$ Altered the way of thinking about diet, exercise, or stress management

- $\quad$ Came to a conclusion about whether to see a physician

- $\quad$ Altered the way of managing with a continuing condition or handling pain.

\section{Reasons Why People used to connect with others}

- To know what others say about a treatment

- To know other people' experiences

- To get emotive support

- $\quad$ To build awareness about a disease

- $\quad$ To share their experiences regarding a treatment

- To share experience about a health issue

- To know others experience about other hospitals.

Patients need proper health information in order get treatment decisions and intensify message with their doctor. Enhanced patient access may increase patient satisfaction with care and lead to better health outcomes. The use of social software and its ability to promote collaboration between patients, their caregivers, medical professionals, and her stakeholders in health. Social media is an ideal platform for patients \& caregivers

\section{DISCUSSION \& CONCLUSION}

This paper and its results, and the subjects it discovers can actually thrust forward the discussion about social media and people's health and Safety. Believe that this study will be converted into action that permits people with the information and tools to circumnavigate social stages online in a path that defends and stimulates their health and wellbeing. Social media isn't going away soon, nor should it. We must be prepared to encourage the revolution that the future holds.

Increasing attention in social media from clients and creators alike has enhanced the progress of new methods of social connections, providing a progressively cherished chance for medical academics interested in the social scopes of health. As more activities are recorded and unavoidably connected with social media, the diversity of strategies offered for discovering the special effects of social interactions on health consequences lasts to increase, creating a field of newfangled opportunities for researchers interested in utilizing the supremacy and pervasiveness of social media to learn the changing aspects of health.

\section{REFERENCES}

[1] Berkman LA, Kawachi I. A historical framework for social epidemiology. In: Berkman L, Kawachi I, eds. Social Epidemiology. New York: Oxford University Press; 2000:3-12.

[2] Centola D, Eguiluz V, Macy M. Cascade dynamics of complex propagation. Physica A. 2007;374:449-456.

[3] Christakis N, Fowler J. Dynamics of Smoking behavior in a large social network. N Engl J Med. 2008;358:2249-2258

[4] Erickson T. Social interaction on the net: virtual community as participatory genre. In: Proceedings of the Thirtieth Annual Hawaii International Conference on System Sciences; Maui, Hawaii: Shidler College of Business, University of Hawaii at Manoa; 1997;6:13-21.

[5] Farrow DC, Hunt WC, Samet JM. Geographic variation in the treatment of localized breast cancer. N Engl J Med. 1992;326:1097-1101.

[6] Hawn C. Take two aspirin and tweet me in the morning: how Twitter, Facebook, and other social media are reshaping health care. Health Aff 


\section{International Advanced Research Journal in Science, Engineering and Technology}

Vol. 8, Issue 8, August 2021

\section{DOI: 10.17148/IARJSET.2021.8866}

(Millwood). 2009;28:361-368.

[7] Kamel Boulos MN, Wheeler S. The emerging Web 2.0 social software: an enabling suite of sociable technologies in health and health care education. Health Info Libr J. 2007;24:2-23

[8] Kawachi I, Berkman LA. Neighborhoods and Health. New York: Oxford University Press; 2003.

[9] Krieger N. A glossary for social epidemiology. J Epidemiol Community Health. 2001;55:693-700.

[10] McNab C. What social media offers to health professionals and citizens. Bull World Health Organ. 2009;87:566

[11]. Salathé M, Khandelwal S. Assessing vaccination sentiments with online social media: implications for infectious disease dynamics and control. PLoS Comput Biol. 2011;7:e1002199

[12] Shipman SA, Lan J, Chang CH, Goodman DC. Geographic maldistribution of primary care for children. Pediatrics. 2011;127:19-27.

[13] Smith K, Christakis N. Social networks and health. Annu Rev Sociol. 2008;34:405-429

[14] Thackeray R, Neiger BL, Hanson CL, McKenzie JF. Enhancing promotional strategies within social marketing programs: use of Web 2.0 social media. Health Promot Pract. 2008;9:338-343. 